\title{
Make your Heartbeats Count
}

\author{
James H O’Keefe* \\ Cardiologist, The Mid America Heart Institute of Saint Luke's Hospital, USA
}

Submission: June 26, 2017; Published: July 21, 2017

*Corresponding author: James H O’Keefe, Cardiologist, The Mid America Heart Institute of Saint Luke’s Hospital, USA, Email: jhokeefemd@gmail.com

\section{Opinion}

Everyone who knew Harriet described her as gentle and good-natured, and she loved it when people visited her, especially when they spoke kindly and rubbed her back. Sure, she spent a lot of time napping, but Harriet also enjoyed swimming nearly every day of her life. Oh, a couple more interest $\neg$ ing things about this unique soul: her favorite food was hibiscus flowers, and she lived to be 177 years old. Harriet was a giant turtle-a Gala $\urcorner$ pagos tortoise to be specific. Charles Darwin captured her as a young turtle and brought her on board his ship, the Beagle, during his round-the-world scientific expedition in 1835. Harriet lived most of her life in an idyllic bo $\urcorner$ tanical garden in Brisbane, Australia, where she finally passed away in 2006.

The heart rate of a Galapagos tortoise is 6 to 10 beats per minute (BPM), and these remarkable creatures have a maximum lifespan of 170 to 190 years. In contrast, a hummingbird in flight has a heartbeat of about 1,260 BPM, and has a life expectancy of about three to five years. We humans typically have a resting heart rate of 65 to $85 \mathrm{BPM}$, and usually live for 75 to 85 years. Statisticians call this an inverse relationship: as the resting heart rate goes up, the life expectancy tends to go down, and vice versa.

\section{Does your heart have a limited number of beats?}

Cardiologist Jamil Tajik, M.D., one of my mentors during my cardiol $\neg$ ogy training at the Mayo Clinic in the 1980s, used to warn me and my best friend, Chip Lavie, that our routine of going for a four-mile run was an exerาcise in wasting heartbeats. He believes in the "limited number of heartbeats theory," so he does his best to avoid strenuous exercise. Ac $\neg$ cording to this hypothesis, each heart is capable of a predestined number of heartbeats, and once they are used up-the lights go out and the party's over. This would explain how Harriet the turtle could live to the ripe old age of 177 , while mice, another spe $\neg$ cies with very rapid heart rates, die of old age after just five years. When you do the math (trust me I have), you will discover that the magic number of heartbeats is about 3 billion. It takes a durable heart to break the 3-billion beats barrier before it gives up the ghost.
In fact, for humans and animals fending for themselves out in the wild, 1.5 billion heartbeats is an average lifespan, and 2 billion is good longevity [1].

\section{How to keep your heart in mint condition}

If you were a car, your heart would be your motor. Indeed, the heart, like an engine, has many moving parts-valves, muscles, arteries and chambers, which do eventually wear out. Strenuous physical activity makes the heart beat faster, so is Dr. Tajik right to as $\urcorner$ sume that by avoiding exercise, he won't wear his heart out as quickly? Will we break down sooner if we spend a lot of time exercising, kind of like when we exceed the 100,000-mile power train warranty on a car?

If your pulse rate averages about $80 \mathrm{BPM}$, your heart will beat over 42 million times in one year. With an average pulse of 80 BPM, by age 72 you will have about 3 billion heartbeats on your ticker. Now let's play with the math a bit. Say you begin a regi $\neg$ men that involves strenuous exercise, such as jogging for 25 minutes three days per week; which by the way meets the recommendations of the CDC Physical Activity Guidelines for Americans. During that 75 minutes you spend jogging each week, your heart rate would rise to about 150 BPM, burning through an extra 5,250 heartbeats per week, which calculates to a less than one percent increase in heartbeats. However, within a month or two as you become physical $\neg$ ly fit, your resting heart rate will fall from 80 to $60 \mathrm{BPM}-\mathrm{a} 25$ percent savings in total heartbeats per day. With a pulse of $60 \mathrm{BPM}$, it takes over 95 years to use up 3 billion heart $\neg$ beats.

At a heart rate of 50 , it will be 105 years before you hit 3 billion heartbeats. By investing as little as 15 minutes two to five times per week doing an aerobic exercise like jogging, or swimming, or biking or gardening, you will likely be able to extend your warranty and get many more trouble-free years from your heart and body. Thus, over a lifetime, staying fit with a moderate exer $\neg$ cise regimen reduces the wear and tear on your heart. In contrast, if you are perpetually training for ultra- 
marathons and doing strenuous exercise for over two hours per day, you will have a nice low resting heart rate, but you will be putting a lot of hard miles on your engine [2].

Dr. Tajik had a valid point when he was warning us against overdoing it with running. An accumulating body of evidence shows that the amazing longevity boost from exercise is largely eliminated by excessive physical activity. Thus, the key is getting your exercise dose into the "Goldiᄀlocks" range: not too little, but not too much either. As usual, moderation is the sweet spot. Training for and doing marathons is not the best lifelong exercise pattern; whereas jogging for 20 to 30 minutes two or four times a week is perfect, or if you prefer, brisk walking or gardening for at least 150 minutes per week is also an ideal activity pattern for bestowing longevity and cardiac durability [3]. My heart will soon beat for its 2 billionth time; I'm shoot 'ing for 3 billion heartbeats. I've decided that I am going to spend more of my remaining heartbeats playing, laughing and enjoying life with my family and friends.

\section{Keeping your heart rate on the down low}

Studies show that in general, people with lower resting heart rates tend to have longer life expectancies. Particularly for males it does not bode well to have a resting heart rate above about 85 or 90 BPM [4]. Even so, women tend to have higher heart rates than men, but often outlive them anyway. We do have medications that will lower your heart rate; including beta blockers (such as carvedilol, metoprolol and nebivolol) or calcium blockers (the one we use most is diltiazem). These are among our most effective drugs for treating common cardiac problems, including high blood pressure, coronary disease, heart failure and rhythm abnormalities such as atrial fibrillation and ventricu $\neg$ lar tachycardia. Fish oil (omega-3) will also lower your resting pulse by about three to five beats per minute, and may pro 7 vide other benefits as well.

Sometimes a higher resting pulse rate may be a symptom, rather than a cause of illness. In other words, an unhealthy diet/lifestyle, obesity, toxic stress, tobacco, excess alcohol and inadequate sleep can all shorten one's lifespan by causing ailments such as heart disease, cancer, stroke and de $\neg$ mentia. As people become sicker, their resting heart rates tend to rise, but it's disease that triggers the higher pulse, rather than the higher pulse that is causing the disease.

\section{Try this at home to lower your resting heart rate}

If someone came up to you and said, "I will give you one million dollars if you can reduce your heart rate to less than 50 BPM in the next 10 minutes," I bet you couldn't do it. Your heart rate is controlled by your autonomic nervous system, operating in an involuntary subconscious fash $\neg$ ion. Your pulse rate rises automatically when you are nervous about being in the doctor's office, or mad because someone cut you off in traffic. On the other hand, your heart rate instinctively falls when you pet your dog, or relax with your partner, or hold your sleeping baby. Importantly, you can learn to lower your own pulse rate, which can reduce stress, improve your sense of well-being and make you feel less anxious and harried. If you follow these steps, you will lower your resting pulse, and also soothe and rejuvenate your heart, and maybe even enhance your longevity; though I wouldn't hold your breath waiting for someone to give you a mil $\neg$ lion dollars.

\section{Practice yoga}

Using the ancient Indian practice of yoga can help you can gain conscious mastery over your cardiovascular system. In scientific studies, people who have never done yoga before learned to lower their resting heart rate by seven to 20 BPM while doing yoga [5]. The traditional techniques of yoga involve breathing, stretching and mindfulness, and when done regularly can reduce the resting heart rate, melt away emotional stress, and calm the mind. A routine of yoga has also been shown to lower blood pressure and reduce occurrences of atrial fibrillation (A-fib).

Meditate. Honestly, sometimes I just need a break from my own thoughts. That is why I meditate-it shifts the thinking brain into neutral. You can do this quickly and easily by occupying your conscious mind with this simple task: breathe slowly and deeply to the rhythm of your heart. Even a couple minutes of this can no-ticeably calm your heart and mind. Close your eyes, sit up straight, breathe in through your nose for the count of 4 and fill up your lungs com $\neg$ pletely, hold the breath for the count of 7, and breathe out slowly for the count of 8 . Try to do this while counting to the rhythm of your heartbeat (by feeling your pulse at your wrist, or sensing your heart beating in your chest, or looking at a pulse monitor). Do this relaxation breathing for four to eight cycles once or twice a day, and you will be officially meditating. This will lower blood pressure and anxiety, and may even prevent depression and improve long-term brain health [6].

\section{References}

1. Geoffrey West (2017) SCALE : The Universal laws of growth, Innovation, Sustainability, and the pace of life, in Organisms, Cities, Economies, and Companies. Publisher: Orion Publishing Group Limited, London, p. 496.

2. O'Keefe JH, Lavie CJ, Guazzi M (2015) Potential dangers of extreme endurance exercise: how much is too much? Prog Cardiovasc Dis 57(4): 396-405.

3. O'Keefe JH, Patil HR, Lavie, CJ, Magalski, A, Vogel RA, et al. (2012) Potential adverse cardiovascular effects from excessive endurance exercise. Mayo Clin Proc 87(6): 587-595.

4. Jensen MT, Suadicani P, Hein HO, Gyntelberg F (2013) Elevated resting heart rate, physical fitness and all-cause mortality: a 16-year follow-up in the copenhagen male study. Heart 99(12): 882-887.

5. Krishna BH, Pal P, GK P, J B, E J, et al. (2014) Effect of yoga therapy on heart rate, blood pressure and cardiac autonomic function in heart failure. J Clin Diagn Res 8(1):14-16.

6. Pal R, Singh SN, Chatterjee A, Saha M (2014) Age-related changes in cardiovascular system, autonomic functions, and levels of BDNF of healthy active males: role of yogic practice. Age (Dordr) 36(4): 9683 
This work is licensed under Creative Commons Attribution 4.0 License DOI: 10.19080/JYP.2017.02.555580

\section{Your next submission with Juniper Publishers will reach you the below assets}

- Quality Editorial service

- Swift Peer Review

- Reprints availability

- E-prints Service

- Manuscript Podcast for convenient understanding

- Global attainment for your research

- Manuscript accessibility in different formats ( Pdf, E-pub, Full Text, Audio)

- Unceasing customer service

Track the below URL for one-step submission https://juniperpublishers.com/online-submission.php 